\title{
Comparison of Oral Health Attitudes and Knowledge among Dental and Medical Students in a Malaysian University
}

\author{
Kishor Tom
}

\begin{abstract}
Objective: The objective of the study was to assess, compare, and analyze the oral health-related knowledge, attitude, and behaviors among medical and dental students.

Materials and methods: A descriptive cross-sectional study was carried out among 241 dental students and 150 medical students from AIMST University, Kedah, Malaysia. The English version of Hiroshima University-Dental Behavioral Inventory (HU-DBI) was used to collect the data regarding the oral health knowledge, attitude, and behavior among the two population. The data were compiled and statistically analyzed using Statistical Program for Social Sciences (SPSS) 16.0 version. Differences in responses were assessed using Chi-square. The level of significance was set at $p<0.05$.

Results: Only $10.37 \%$ of the dental students and $34 \%$ of medical students complained of bleeding gums while brushing their teeth. A high percentage of dental students $(73.86 \%)$ are bothered about the color of the gums, while comparatively less percentage of medical students (58.67\%) are bothered about the color of the gums. As far as toothbrushing is concerned, $91.70 \%$ of dental students brush their teeth carefully, but only $76 \%$ of medical students do it carefully. A higher percentage of medical students $(22.67 \%)$ were not taught professionally to brush their teeth but only a less percentage of dental students (3.32\%).

Conclusion: As per the present study the awareness among the medical students about oral health care and practices was comparable to that of the dental students.

Keywords: Dental students, Hiroshima University-Dental Behavioral Inventory, Medical students, Oral health awareness.

Journal of Oral Health and Community Dentistry (2020): 10.5005/jp-journals-10062-0060
\end{abstract}

\section{INTRODUCTION}

Health is considered to be one of the basic needs of humanity. Oral health is an integral part of general health and essential for well-being. ${ }^{1}$ A healthy oral cavity reflects good general health of a person and it can also be considered as a gateway to good health. Oral hygiene being a tool for assessing one's risk of various oral problems and it depends upon various barriers involving affordability, cultural preferences, and lack of adequate services and technology. A dentist's attitude and awareness regarding oral health are important factors in the maintenance of oral health. ${ }^{2}$ The Hiroshima University-Dental Behavioral Inventory (HU-DBI) was developed by Kawamura to explore and understand the oral health attitudes and behavior of patients in toothbrushing. It not only has good test-retest reliability but also can be useful for predicting clinical outcomes. ${ }^{3,4}$ The HU-DBI which was originally in Japanese language has been translated to English, Finnish, Chinese, and Korean for cross-cultural comparisons. Results for these translated versions have been reported previously. ${ }^{5-9}$

As far as the delivery of oral health care to the community is concerned, the dental institutions play a pivotal role as they act as a training ground for future dentists, and it also helps them in acquiring latest scientific knowledge in dental care through research. The dental institutions also provide students with sufficient knowledge and skills to serve the community in resolving the oral health problems. A dental student understands the importance of self-oral care in the dental school and it imparts a direct positive influence on the society in the matter of oral healthcare awareness.

The patients may seek the help of a medical general practitioner for their oral health-related problems in many places around the
Department of Dental Public Health, AIMST University, Sememling, Kedah, Malaysia

Corresponding Author: Kishor Tom, Department of Dental Public Health, AIMST University, Sememling, Kedah, Malaysia, Phone: +0060164553712, e-mail: kishortom@gmail.com

How to cite this article: Tom K. Comparison of Oral Health Attitudes and Knowledge among Dental and Medical Students in a Malaysian University. J Oral Health Comm Dent 2020;14(1):11-13.

Source of support: Nil

Conflict of interest: None

globe, as even now the access to dental care is limited in many countries especially in the rural areas..$^{10}$ In this scenario, it is advisable for the general medical practitioners to have a basic knowledge about the common dental problems and its treatment, so as to provide appropriate advice to these patients and to fulfill their role as public health educators. ${ }^{11}$

Hence, the present study was carried out to assess and compare the oral hygiene practices, problems, awareness, and habits among the medical students to that of the dental students in AIMST University, Kedah, Malaysia.

\section{Materials and Methods}

All the dental students of AIMST dental institute $(n=241)$ (year 1 to year 5) were recruited into this study from AIMST University, Kedah Malaysia. These data were then compared with 150 medical students doing their year 3 medicine in the AIMST medical faculty using the modified English version of HU-DBI. Willingness of the student to participate in this survey was considered as an inclusion

(c) The Author(s). 2020 Open Access This article is distributed under the terms of the Creative Commons Attribution 4.0 International License (https://creativecommons. org/licenses/by-nc/4.0/), which permits unrestricted use, distribution, and non-commercial reproduction in any medium, provided you give appropriate credit to the original author(s) and the source, provide a link to the Creative Commons license, and indicate if changes were made. The Creative Commons Public Domain Dedication waiver (http://creativecommons.org/publicdomain/zero/1.0/) applies to the data made available in this article, unless otherwise stated. 
criterion for the study. Year 3 medical students were taken for the study as they have just entered the clinical years and they are the only group of clinical students available at the university. This research was approved by the AIMST University Research Ethics Committee with the approval no: AUHAEC15/FOD/2016. We obtained a written signed consent from all the participants of the survey.

The study sample of dentistry students of AIMST Dental Institute and year 3 medical students of the same university were enlisted for comparison. Explanation regarding the objectives of the study and the scoring criterion for different items of the survey was provided to the participants. The investigators were available throughout to answer any query regarding the inventory. The research team was available throughout the survey process to clear any doubts of the participants regarding the questionnaire. The respondents were asked to fill in the spaces with two responses only, yes or no.

The data were coded and subjected to descriptive statistical analysis. Chi-square test was used to check the significance of different variables, and the level of significance was set at $p<0.05$.

\section{Results}

A total of 241 (61.64\%) dental students and 150 (38.36\%) year 3 medical students participated in the survey with a $100 \%$ response rate. All participants were between 18 years and 25 years of age. Table 1 compares the responses by the dental students and the medical students. Among the respondents, $89.63 \%$ of the dental students responded that they do not worry much about visiting the dentist; on the contrary, $67.33 \%$ of the medical students responded in the same way. Only $10.37 \%$ of the dental students and $34 \%$ of medical students complained of bleeding gums while brushing their teeth. Among the dental students, 31.95\% noticed white sticky deposits on the tooth, while $50.67 \%$ of medical students noticed it. A high percentage of dental students (73.86\%) are bothered about the color of the gums, while comparatively less percentage of medical students (58.67\%) are bothered about the color of the gums. As far as toothbrushing is concerned, $91.70 \%$ of dental students brush their teeth carefully but only $76 \%$ of medical students do it carefully. A higher percentage of medical students (22.67\%) were not taught professionally to brush their teeth but only a less percentage of dental students (3.32\%) were included into that category. It is found that $97.51 \%$ and $81.33 \%$ of the dental and medical students, respectively, look at their teeth in the mirror after brushing; this has got a good statistical significance $(<0.0001)$ and may be because dental students have more theoretical knowledge about the esthetics of oral structures than the medical students. A high proportion of dental students (90.87\%) and medical students (76.67\%) were worried about having bad breath, respectively. Among the respondents, $90.46 \%$ of the dental students opined that prevention of gum disease is not possible with toothbrushing alone, while $78.67 \%$ medical students opined in the same way. It was also noted that $57.26 \%$ of the dental students postpone going to the dentist until they have a toothache, but only $44.67 \%$ of the medical students put off visiting the dentist. Regarding toothbrushing, $75.93 \%$ of dental students do not feel they have brushed well, unless they do it with strong strokes, while only $55.33 \%$ of the medical students feel that way.

\section{Discussion}

As the medical and dental students are the future health professionals, they should possess precise knowledge of oral health practices in their university years. The oral health status of a health practitioner gives an insight not only into his/her health and quality of life but also into his/her attitude and behavior toward health. The oral health knowledge, behavior, and status of these students are of great significance to themselves and their patients.

In this study, it is also found out that there are some deficits in the knowledge and awareness about oral health practices among dental and medical students. Among the dental students, $10.37 \%$ had bleeding gums. Similar kind of study which was conducted in Australia showed a lower proportion (6\%) ${ }^{6}$ among Australian dental students. But a study did show a higher trend in the proportion of bleeding gums among Finnish (45\%) and Japanese (25\%) dental student population, respectively. ${ }^{7}$ As far as the prevention of gum diseases is concerned, $90.46 \%$ of the dental students and $78.67 \%$ of the medical students believed that it was impossible to prevent gum disease with toothbrushing alone, and most of the students in the two populations were worried about halitosis.

On an average, $73.86 \%$ of the dental students and $58.67 \%$ of the medical students were worried about the color of their gums; $97.51 \%$ of the dental students and $81.33 \%$ of the medical students

Table 1: Responses of dental and medical students

\begin{tabular}{|c|c|c|c|c|c|}
\hline S. no. & Item & Dental students, $n(\%)$ & Medical students, $n$ (\%) & Total, $n$ (\%) & pvalue \\
\hline 1 & I do not worry much about visiting the dentist & $216(89.63)$ & $101(67.33)$ & $317(81.1)$ & $<0.0001$ \\
\hline 2 & My gums tend to bleed when I brush my teeth & $25(10.37)$ & $51(34.00)$ & $76(19.43)$ & $<0.0001$ \\
\hline 3 & I have noticed some white sticky deposits on my teeth & 77 (31.95) & $76(50.67)$ & $153(39.13)$ & 0.0003 \\
\hline 4 & I am bothered by the color of my teeth & $176(73.02)$ & $90(60.00)$ & $266(68.03)$ & 0.0025 \\
\hline 5 & I am bothered by the color of my gums & $178(73.86)$ & $88(58.67)$ & $266(68.03)$ & 0.0025 \\
\hline 6 & I brush each of my teeth carefully & $221(91.70)$ & $114(76.00)$ & $335(85.67)$ & $<0.0001$ \\
\hline 7 & I have never been taught professionally how to brush & $8(3.32)$ & $34(22.67)$ & $42(10.74)$ & $<0.0001$ \\
\hline 8 & I often check my teeth in a mirror after brushing & $235(97.51)$ & $122(81.33)$ & $357(91.30)$ & $<0.0001$ \\
\hline 9 & I worry about having bad breath & $219(90.87)$ & $115(76.67)$ & $334(85.42)$ & 0.0002 \\
\hline 10 & $\begin{array}{l}\text { It is impossible to prevent gum disease with toothbrush } \\
\text { alone }\end{array}$ & $218(90.46)$ & $118(78.67)$ & $336(85.93)$ & 0.0019 \\
\hline 11 & I put off going to the dentist until I have a toothache & $138(57.26)$ & $67(44.67)$ & $205(52.42)$ & 0.0157 \\
\hline 12 & $\begin{array}{l}\text { I do not feel I have brushed well unless I brush with strong } \\
\text { strokes }\end{array}$ & $183(75.93)$ & $83(55.33)$ & $266(68.03)$ & $<0.0001$ \\
\hline 13 & I feel I sometimes take too much time to brush my teeth & $84(34.85)$ & $32(21.33)$ & $116(29.66)$ & 0.0063 \\
\hline 12 & Journal of Oral Health and Community Dentistry, Volume 14 Issu & 1 (January-April 2020) & & & 2 \\
\hline
\end{tabular}


checked their teeth in the mirror after brushing. About $73.02 \%$ of the dental students were concerned about the color of their teeth. In a similar study conducted on Jordanian dental students, it was reported that $67 \%$ of Jordanian dental students are concerned about the color of their teeth. ${ }^{12}$ Hence, this proves a significant concern for esthetics among dental and medical students.

At the same time, it was noted that around $4 \%$ of the dental students have never been exposed to professional training with regard to toothbrushing and $57.26 \%$ of the dental students postpone visiting a dentist until they have a toothache. As far as satisfaction regarding toothbrushing is concerned, $75.93 \%$ of them do not feel satisfied with their toothbrushing unless they do it with strong strokes. Around $22 \%$ of the respondents among the medical students had never received a professional training in toothbrushing, and $45 \%$ of them indicated that they do not visit a dentist until they had a toothache. Thus, it has become a necessity that healthcare professional students should recognize the significance of preventive oral health care, so that they can make their patents aware of the same.

\section{Conclusion}

A well-informed and positively reinforced patient complies better with oral healthcare regimens. Among the population, the main reason for nonadherence to oral hygiene practices is the lack of information. Health professionals play a key role in providing information to the patients about the best oral health practices. Present research concluded that oral health-related knowledge, attitude, and behavior of dental students are better than that of the medical students. In this study, it is also found that there are some deficits in the knowledge and awareness about oral health practices among dental and medical students. As far as the knowledge about good oral health practices of these study populations are concerned, they both show a positive trend. Oral health education should be taught to all health professional students by arranging dental/oral health-related campaigns, so as to achieve an improved oral health for the general population by the combined efforts of oral and medical health practitioners.

\section{References}

1. Petersen PE. The world oral health report 2003: continuous improvement of oral health in the 21st century-the approach of the WHO global oral health programme. Community Dent Oral Epidemiol 2003;31(Suppl 1):3-24. DOI: 10.1046/j.2003.com122.x.

2. KassakKM, Dagher R, Doughan B. Oral hygiene and lifestyle correlates among new undergraduate university students in Lebanon. J Am Coll Health 2001;50(1):15-20. DOI: 10.1080/07448480109595706.

3. Kawamura M. Dental behavioral science. The relationship between perceptions of oral health and oral status in adults. Hiroshima Daigaku Shigaku Zasshi 1988;20(2):273-286. (in Japanese).

4. Kawamura M, Sasahara H, Kawabata K, et al. Relationship between CPITN and oral health behaviour in Japanese adults. Aust Dent $J$ 1993;38(5):381-388. DOI: 10.1111/j.1834-7819.1993.tb05520.x.

5. Kawamura M, Kawabata K, Sasahara H, et al. Dental behavioral science. PartIX. Bilinguals' responses to the dental behavioral inventory (HU-DBI) written in english and in Japanese. Hiroshima Daigaku Shigaku Zasshi 1992;24:185-191. (in Japanese).

6. Kawamura M, Iwamoto Y, Wright FA. A comparison of self-reported dental health attitudes and behavior between selected Japanese and Australian students. J Dent Educ 1997;61(4):354-360.

7. Kawamura $\mathrm{M}$, Honkala E, Widström $\mathrm{E}$, et al. Cross-cultural differences of self-reported oral health behaviour in Japanese and Finnish dental students. Int Dent J 2000;50(1):46-50. DOI: 10.1111/j.1875-595x.2000. tb00546.x.

8. Kawamura M, Yip H-K, Hu D-Y, et al. A cross-cultural comparison of dental health attitudes and behaviour among freshman dental students in Japan, Hong-Kong and West China. Int Dent J 2001;51(3):159-163. DOI: 10.1002/j.1875-595x.2001.tb00833.x.

9. Kim K-J, Komabayashi T, Moon S-E, et al. Oral health attitudes/ behavior and gingival self-care level of Korean dental hygiene students. J Oral Sci 2001;43(1):49-53. DOI: 10.2334/josnusd.43.49.

10. IIm WU, King NM, Tsai JSJ, et al. Dental knowledge and attitude of medical practioners and care givers of preschool children in Macau. British J Oral and Maxillofacial Surgery 2005;43(1):61-64. DOI: 10.1016/j.bjoms.2004.08.023.

11. Naidu RS, Juman S, Rafeek RN, et al. Oral and dental conditions presenting to medical practitioners in Trinidad and Tobago. Int Dent J 2008;5(4):194-198. DOI: 10.1111/j.1875-595x.2008.tb00348.x.

12. Al-Omari QD, Hamasha AA. Gender-specific oral health attitudes and behavior among dental students in Jordan. J Contemp Dent Pract 2005;6(1):107-114. DOI: 10.5005/jcdp-6-1-107. 